\title{
Hidrelétricas nos rios formadores do pantanal: ameaças à conservação e às relações socioambientais e econômicas pantaneiras tradicionais
}

O estudo analisa e questiona a implantação de usinas hidrelétricas no planalto circundante à planície pantaneira. Foram identificados 165 empreendimentos, dentre os que estão em operação (45), outorgados (11), eixo disponível (56), Plano Básico Ambiental aceito (47) e com registro (02), além de empreendimentos suspensos (02) e revogados (02). Desse montante, 116 empreendimentos estão em processo de análise, em especial no Mato Grosso, responsável pela maior parte da água que supre todo o sistema da Bacia do Alto Paraguai/Pantanal matogrossense Observa-se que, para a implantação dos empreendimentos, inexiste planejamento na bacia hidrográfica no tocante à questão ecológica, às populações pré-existentes e suas atividades socioeconômicas. Do total de 169 empreendimentos, a maioria é de pequenas centrais hidrelétricas, muitas em um mesmo rio. Há apreensão na sociedade civil e na comunidade científica, pois os gestores públicos privilegiam a atividade de geração de energia hidrelétrica, alegando a crescente demanda do país, favorecendo o setor elétrico em detrimento da existência científica, pois os gestores públicos privilegiam a atividade de geração de energia hidrelétrica, alegando a crescente demanda do país, favorecendo o setor elétrico em detrimento da existência dos demais usos preponderantes e tradicionais da região que possuem como economia a pesca profissional-artesanal e a de subsistência, o turismo - em suas várias vertentes (ecológico, de pesca, cultural, rural, de base comunitária, de aventura etc.) e a pecuária tradicional, práticas que convivem com o equilibrio ambiental do bioma quanto ao seu funcionamento hidro Conclui-se que a implantação das Pequenas Centrais Hidrelétricas (PCHs) trará agravos e implicações socioambientais a um ambiente frágil e de elevada importância social e sua preservação deve ser garantida pela legislação. Propõe-se diálogo e alternativas ao modelo de desenvolvimento de exploração energética.

Palavras-chave: Impactos Socioambientais; Hidrelétricas; Pantanal.

\section{Hydroeletric in the rivers that form pantanal: threats to conservation and to Pantanal traditional socio-environmental and economic relations}

\begin{abstract}
The study analyzes and questions the implantation of hydroelectric plants in the plateau surrounding the Pantanal plain. There were identified 165 enterprises, among those that are in operation (45), granted (11), available axis (56), Environmental Basic Plan accepted (47) and with registration (02), besides suspended projects (02) and revoked (02). Of this amount, 116 projects are under analysis process, especially in Mato Grosso, accountable for most part of the water that supply the entire system of the Bacia do Alto Paraguai/Pantanal Mato Grossense. It is observed that, for implementation of the enterprises, there is no planning in the hydrographic basin regarding the ecological issue, the pre-existing populations and their socioeconomic activities. Of the total of 169 enterprises, most are small hydroelectric plants, many in the same river. There is apprehension in civil society and scientific community, because the public managers favor the activity of hydroelectric power generation, alleging the growing demand of the country, favoring the electric sector in detriment of the existence of other preponderant managers favor the activity of hydroelectric power generation, alleging the growing demand of the country, favoring the electric sector in detriment of the existence of other preponderant
and traditional uses of the region that have as economy, the professional-artisanal fishing, tourism - in its various aspects (ecological, fishing, cultural, rural, community-based, adventure, etc.) and traditional livestock, practices that coexist with the environmental balance of the biome as its hydro ecological operation and enjoy it. Such activities are the main responsible for the job generation and income in the region, besides the fishing guarantee the traditional populations' food security. It is concluded that the implementation of Small Hydro Power (SHP) will bring social and environmental problems and implications to a fragile environment of high social importance and its preservation must be guaranteed by legislation. It proposes dialogue and alternatives to the energy exploration development model.
\end{abstract}

Keywords: Socioenvironmental Impacts; Hydroelectric; Pantanal.

Topic: Desenvolvimento, Sustentabilidade e Meio Ambiente

Reviewed anonymously in the process of blind peer.

Débora Fernandes Calheiros (iD)

Universidade de São Paulo, Brasil

http://lattes.cnpq.br/6343238272229162

http://orcid.org/0000-0003-4893-7890

debora.calheiros@embrapa.br

Solange Kimie Ikeda Castrilon (ic

Universidade do Estado do Mato Grosso, Brasil

http://lattes.cnpq.br/3373034135331436

http://orcid.org/0000-0003-1862-4615

ikedac@gmail.com

Aumeri Carlos Bampi

Universidade do Estado de Mato Grosso, Brasil

http://lattes.cnpq.br/4800812434410023

http://orcid.org/0000-0002-3410-9376

profaumericarlosbampi@gmail.com

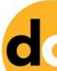

DOI: 10.6008/CBPC2179-6858.2018.001.0009
Received: 02/02/2018 Approved: 20/05/2018
Referencing this:

CALHEIROS, D. F.; CASTRILON S. K. I.; BAMPI, A. C.. Hidrelétricas nos rios formadores do pantanal: ameaças à conservação e às relações socioambientais e econômicas pantaneiras tradicionais. Revista lberoAmericana de Ciências Ambientais, v.9, n.1, p.119-139, 2018. DOI: http://doi.org/10.6008/CBPC2179-6858.2018.001.0009 


\section{INTRODUÇÃO}

A implantação de mais de uma centena de usinas hidrelétricas no planalto circundante à planície pantaneira, sem planejamento no tocante a toda bacia hidrográfica, tem gerado apreensão na sociedade civil e na comunidade científica. Foram identificados 165 empreendimentos, dentre os que estão em operação (45), outorgados (11), sob eixo disponível (56), com Plano Básico Ambiental (PBA) aceito (47) e com registro (02), além de empreendimentos suspensos (02) e revogados (02). Há 116 empreendimentos que estão em processo de análise atualmente, em especial no Pantanal Norte, em Mato Grosso, responsável pelo suprimento da maior parte da água de todo o sistema Bacia do Alto Paraguai/Pantanal mato-grossense. Diante desse contexto, este estudo objetiva analisar e discutir as implicações ambientais e sociais da implantação dos empreendimentos hidrelétricos planejados no Pantanal mato-grossense.

Atualmente, os números já indicam um total de 169 empreendimentos, a maioria de pequenas centrais hidrelétricas, muitas construídas ou planejadas em um mesmo rio. Os gestores federais e estaduais de Mato Grosso e Mato Grosso do Sul, em geral, privilegiam a atividade de geração de energia hidrelétrica, alegando a crescente demanda do país, favorecendo o setor em detrimento dos demais usos preponderantes e tradicionais da região.

As atividades econômicas tradicionais da planície pantaneira como a pesca profissional-artesanal e a de subsistência, o turismo - em suas várias vertentes (ecológico, de pesca, cultural, rural, de base comunitária, de aventura etc.) - e a pecuária tradicional, dependem diretamente da saúde ambiental do Pantanal, em especial quanto ao seu funcionamento hidro ecológico. A pesca profissional-artesanal e a turística são as principais responsáveis pela geração de emprego e renda na região, além de garantir a segurança alimentar por meio da pesca de subsistência.

A Constituição Federal, em seu artigo 225 (BRASIL 1988), determina a conservação dos recursos naturais do bioma Pantanal, uma vez que a região é considerada patrimônio nacional, impondo-se ao Poder Público e à coletividade o dever de defendê-lo e preservá-lo para as presentes e futuras gerações, sendo que sua utilização far-se-á, na forma da lei, dentro de condições que assegurem a preservação do meio ambiente, inclusive quanto ao uso dos recursos naturais. Cabe ainda ao Poder Público preservar e restaurar os processos ecológicos essenciais e prover o manejo ecológico das espécies e ecossistemas.

A Lei de Recursos Hídricos (Lei no 9.433/1997; BRASIL 1997a) determina que a gestão deve estar baseada no respeito aos Usos Múltiplos das Águas, ou seja, todos têm direito de acesso a esse bem público, não se podendo privilegiar, portanto, apenas um ou alguns setores usuários. Além disso, o planejamento e a gestão das águas devem ser feitos na totalidade da bacia hidrográfica, neste caso, a Bacia Hidrográfica do Alto Paraguai (BAP) e a gestão deve ser descentralizada e participativa por meio dos Comitês de Bacia Hidrográfica e Conselhos Estaduais e Nacional de Recursos Hídricos (CNRH); contudo, não há ainda um Comitê Federal da Bacia do Alto Paraguai implantado e poucos são os Comitês de Bacia em atividade (quatro em Mato Grosso e um em Mato Grosso do Sul). Esses Comitês, bem como os Conselhos Estaduais, no entanto, não têm atuado de forma efetiva frente à gravidade das ameaças à conservação dos recursos hídricos e dos processos hidro 
ecológicos essenciais ao bioma Pantanal, nem quanto a prover o manejo ecológico das espécies e ecossistemas.

A região também é considerada uma das maiores áreas úmidas do mundo pela Convenção de Ramsar - Convenção sobre Áreas Úmidas de Importância Internacional, cujo país é signatário desde 1992 (RAMSAR 2016), tendo, portanto, o compromisso internacional de corresponder aos seus princípios.

O Pantanal brasileiro conta com três Sítios Ramsar, ou seja, áreas úmidas de importância internacional: Parque Nacional do Pantanal Mato-Grossense, MT/MS, Reserva Particular do Patrimônio Natural (RPPN) SESC Pantanal, MT e RPPN Fazenda Rio Negro, MS. O Pantanal mato-grossense tem ainda o título de Patrimônio Natural da Humanidade e Reserva da Biosfera pela UNESCO (2000ab).

Contudo, apesar das prerrogativas para sua conservação, aliadas a outros importantes princípios como os da Prevenção e da Precaução, que deveriam com obviedade ser considerados pelos gestores públicos, quando a questão é geração de energia com o envolvimento de um setor extremamente influente política e economicamente, tais salvaguardas não são levadas em consideração.

Para a conservação de um ecossistema e dos benefícios (serviços ecossistêmicos) que gera para toda a sociedade, é necessário que os usos de seus recursos naturais respeitem aos seus limites ou à sua capacidade de suporte e de resiliência (MEA 2005 a, b). No caso do Pantanal, por ser uma extensa planície de inundação, geomorfologicamente formada pela junção das planícies de inundação dos seus rios formadores, tais limites de sustentabilidade implicam necessariamente em respeitar à dinâmica natural das águas, os chamados pulsos de inundação (JUNK et al., 1989; NUNES DA CUNHA et al., 2015).

Os pulsos de inundação, ou os ciclos de cheia e seca sazonais e interanuais, relacionam-se não só à dinâmica das águas (POSTEL; RICHTER 2003; COLLISCHONN et al., 2005), mas também ao fluxo natural de sedimentos (CARVALHO et al., 2008; SILVA et al., 2011; SOUZA, 2013) e nutrientes (HAMILTON et al., 1997; CALHEIROS; HAMILTON, 1998; CALHEIROS, 2003; BASTIVIKEN et al., 2010; OLIVEIRA et al., 2010, 2011; REZENDE et al., 2012; ANDRADE et al., 2015) que regem a geomorfologia e os ciclos biogeoquímicos, respectivamente, desse extenso ecossistema e sustentam, por conseguinte, uma elevada produção pesqueira, bem como as relações sociais, econômicas e culturais da sociedade pantaneira. Essa elevada produção, por sua vez, é responsável pela pujança da atividade pesqueira, tanto profissional quanto turística, de elevada importância cultural, social e econômica (SILVA; SILVA, 1995; CATELLA; PETRERE, 1996; MORAES; SEIDL, 2000; CALHEIROS et al., 2000; CATELLA, 2001; SHRESTHA et al., 2002; ALBUQUERQUE et al., 2013; CATELLA et al., 2015).

\section{METODOLOGIA}

O estudo foi realizado a partir de revisão bibliográfica sobre o funcionamento hidro ecológico do Pantanal mato-grossense e buscou expor os impactos ambientais de Pequenas Centrais Hidrelétricas e suas implicações socioambientais, tendo por base a participação ativa em reuniões, conselhos e audiências públicas com estudo em profundidade dos relatórios de impacto ambiental dos empreendimentos hidrelétricos em processo de licenciamento na Bacia do alto Paraguai (BAP). 
Para a análise documental foram consultados documentos públicos e oficiais relacionados ao tema: Estudos hidrológicos da Bacia do Alto Paraguai (BRASIL, 1974), Estudo de desenvolvimento integrado da Bacia do Alto Paraguai (BRASIL, 1981), Política nacional de recursos hídricos (BRASIL, 1997a), Plano de conservação da Bacia do Alto Paraguai (Pantanal): PCBAP (BRASIL, 1997b), Diagnóstico analítico do Pantanal e Bacia do Alto Paraguai: implementação de práticas de gerenciamento integrado de bacia hidrográfica para o Pantanal e Bacia do Alto Paraguai (BRASIL. 2003), Caderno da região hidrográfica do Paraguai (BRASIL, 2006a), Boletim mensal de monitoramento do sistema elétrico brasileiro (BRASIL, 2016), Sistema de informações georreferenciadas do setor elétrico (ANEEL, 2018).

Posteriormente foram analisadas entrevistas realizadas pelo Instituto Gaia, em 2012, que deram origem ao vídeo $\mathrm{O}$ dia em que o rio secou. O teor desses depoimentos - informações relativas aos impactos socioambientais da pesca - foi sistematizado para este trabalho.

\section{REVISÃO TEÓRICA}

\section{O Pantanal Mato-Grossense}

O principal rio da Bacia Hidrográfica do Alto Paraguai (BAP) e principal canal de drenagem de toda a planície pantaneira é o rio Paraguai, com uma extensão total de $1.683 \mathrm{~km}$ no Brasil. Nasce no estado do Mato Grosso, na região do Planalto dos Parecis, que é o grande divisor de águas entre a bacia Amazônica e a Platina e corre em direção ao sul até o rio Apa, em Porto Murtinho (Mato Grosso do Sul), passando a pertencer ao país Paraguai. A BAP inclui a área de drenagem do planalto circundante à planície pantaneira e é parte integrante da Bacia do Prata, com uma área de 496.000 km², compartilhada por Brasil, Bolívia e Paraguai. Em território brasileiro, a área da bacia é de $362.259 \mathrm{~km}^{2}$, abrangendo 52\% em Mato Grosso e $48 \%$ em Mato Grosso do Sul, sendo $214.685 \mathrm{~km}^{2}$ de planalto e $147.574 \mathrm{~km}^{2}$ de planície (BRASIL 2006a) (figura 1).

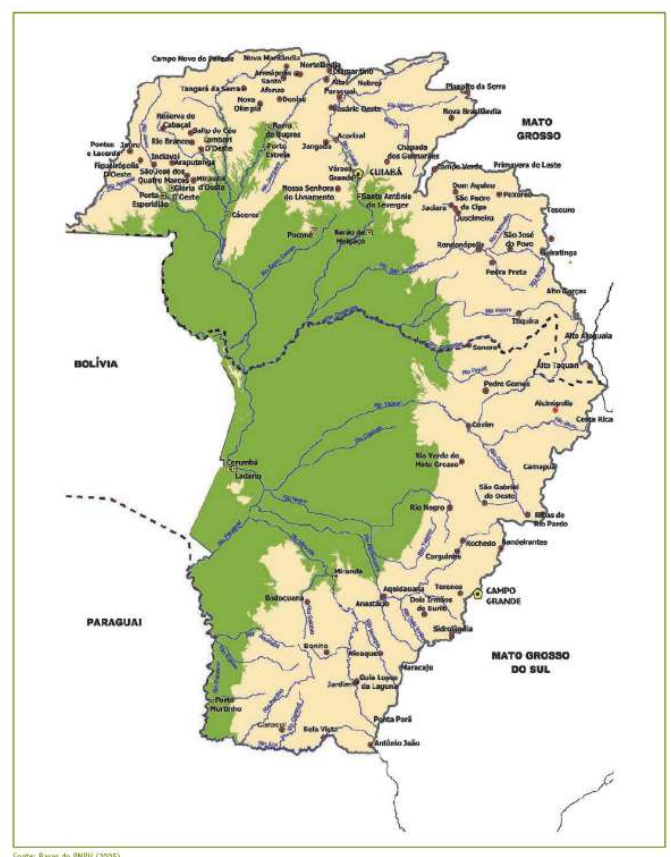

Figura 1 - Bacia do Alto Paraguai e Pantanal mato-grossense no Brasil, evidenciando o planalto com a localização das principais cidades e rios formadores do Pantanal (verde). Fonte: BRASIL (2006a) 
A região denominada Pantanal, ou planície pantaneira, compreende as áreas abaixo de 200 metros de altitude, que dependem sobremaneira das interações com o planalto localizado em seu entorno, incluindo as nascentes dos seus vários rios formadores (figura 1). A dependência e as inter-relações entre planície pantaneira e planalto são preponderantes para o funcionamento do bioma Pantanal, bem como é a principal fonte dos vários impactos antrópicos resultantes do uso dos recursos naturais, em especial o uso do solo que possui atividades de pecuária e agricultura. Portanto, os desafios para promover a gestão regional das águas pressupõem o entendimento das relações entre as funções que ocorrem no planalto e na planície, bem como a responsabilidade perante os demais países da Bacia do Paraguai: Bolívia, Paraguai e o norte da Argentina (BRASIL 2006a).

Sua localização, incrustada no centro da América do Sul, confere à extensa planície de inundação do Pantanal uma grande variedade de fauna e flora, influenciadas pelas regiões contíguas da Amazônia, do Chaco, do Cerrado e da Mata Atlântica, que contribuem para sua diversidade biológica, sustentada pelo regime de todo o sistema fluvial, com elevada abundância de populações faunísticas, em especial das oficialmente listadas como ameaçadas de extinção em outros biomas do país como arara azul, onça parda, onça pintada, cervo do pantanal, ariranha e lontra (BRASIL 2006a).

Nessa região hidrográfica, em virtude de sua extensa planície de inundação, há influência das estações do ano e do regime de chuvas (de outubro a março - período chuvoso - e de abril a setembro período seco) nas vazões de cada um de seus afluentes e no rio Paraguai, em seu trecho superior. Nos trechos médio e inferior do rio Paraguai, o período de maiores e menores vazões é diferenciado dos seus afluentes, o que demonstra a importância que o Pantanal possui para a regularização das vazões do rio Paraguai (BRASIL 2006a). Isso se dá devido à predominância dos solos arenosos na planície e às suas características geomorfológicas e de relevo, incluindo a extensa planície de inundação. Extensas áreas permanecem submersas por inundação (rios) ou alagamento (chuvas e elevação do nível do lençol freático) por até oito meses de um ano hidrológico.

No Pantanal, a área submersa pode atingir cerca de $70 \%$ da área total, considerando-se as áreas inundadas/alagadas classificadas como de média e longa duração (4-6 meses e 6-8 meses, respectivamente) (BRASIL 1974). Dessa forma, o Pantanal funciona como um grande reservatório que retém a maior parte da água oriunda do planalto e regulariza a vazão do rio Paraguai em até seis meses entre as vazões de entrada e saída. Devido às características geomorfológicas e hidrodinâmicas, a onda de cheia só atinge a região de Corumbá dois ou três meses depois e a região de Porto Murtinho cerca de seis meses depois do evento (CARVALHO 1986).

O pulso de inundação é o fator principal que rege o funcionamento de rios com planície de inundação (JUNK et al., 1989; NUNES DA CUNHA et al., 2015). No Pantanal, o ciclo anual de cheias e secas rege a dinâmica biogeoquímica, bem como a estrutura e a dinâmica da biodiversidade, pois ora favorece as espécies animais e vegetais relacionadas à fase de seca, ora favorece as espécies relacionadas à fase de cheia. Além disso, uma fase favorece a outra, à medida que, por exemplo, as espécies vegetais que se desenvolveram na fase seca e que morreram durante a inundação fornecerão nutrientes e sais à água como resultado da decomposição 
desta matéria orgânica submersa, os quais contribuirão para o desenvolvimento das espécies vegetais da fase aquática subsequente e vice-versa. Essa dinâmica das águas promove a dinâmica de organismos aquáticos (CALHEIROS; HAMILTON 1998; OLIVEIRA; CALHEIROS 2000; CALHEIROS 2003; ANDRADE 2011; SANTOS et al., 2013), além de modular também a dinâmica da flora e da fauna terrestres (ALHO, 2008, 2011a; ALHO et al., 2011; SCREMIN-DIAS et al., 2011; POTT et al., 2011ab; MOURÃO et al., 2013).

Ainda segundo Junk e colaboradores (1989), a manutenção de um estado inicial de sucessão nessas planícies, em consequência da renovação constante decorrente do pulso de inundação, favorece a alta produtividade. A produção no ambiente aquático depende da natureza do pulso de inundação. Em bacias com rápidas taxas de drenagem, como, por exemplo, em rios ou trechos de rios em áreas altas como no planalto, uma chuva tem como consequência um aumento rápido das vazões seguido por quedas rápidas, o que não é vantajoso à biota aquática em termos adaptativos. No Pantanal, o deslocamento lento da água pela interação dos rios com suas respectivas planícies de inundação, com o amortecimento dos picos de cheia, propicia tais condições de alta produtividade.

Portanto, o chamado pulso de inundação, a variação sazonal das cheias e secas anuais e plurianuais, é determinante para o funcionamento hidro ecológico da planície pantaneira e qualquer alteração antrópica na periodicidade, duração e magnitude das fases de inundação ou de seca afetará os processos ecológicos que regem o sistema Pantanal, que deveriam ser protegidos conforme determina a Constituição Brasileira (1988).

\section{Impactos Ambientais}

A fragmentação de rios é o maior impacto para um sistema cuja característica principal é o fluxo dinâmico de suas águas e periodicidade sazonal. Os barramentos fragmentam habitats, alteram a biodiversidade e impedem a migração reprodutiva de peixes, além de reter água, nutrientes e sedimentos, alterando o fluxo natural desses elementos fundamentais para o funcionamento dinâmico de uma planície de inundação.

As Pequenas Centrais Hidrelétricas - PCHs; (geração de energia entre $>5 \mathrm{MW} \mathrm{e}<30 \mathrm{MW}$,), em sua maioria previstas para a BAP (86\%), praticamente não apresentam reservatórios, pois operam "a fio d'água", não retendo água de forma significativa, mas impedem o deslocamento reprodutivo dos peixes migratórios rio acima. A presença de uma barreira física sabidamente impede a movimentação das espécies de peixes migratórios na fase de piracema, afetando a produção pesqueira em médio e longo prazo (WELCOMME, 1995; FERNANDES et al., 2009).

As PCHs podem promover também a retenção de nutrientes e sedimentos, ainda que em pequena magnitude, pois, quando construídas em série em um mesmo rio, num arranjo denominado "em cascata", podem potencialmente alterar, em conjunto, a hidrodinâmica natural das águas, afetando tanto a quantidade como a qualidade, retendo ou diminuindo o fluxo de sedimentos e organismos e, por conseguinte, modificar o funcionamento de um rio a jusante, nas áreas da planície. Assim, o efeito conjunto e sinérgico de várias PCHs previstas em um mesmo rio, como previsto na BAP (figura 2), podem promover potencialmente 
impactos ambientais na mesma ordem de magnitude dos provocados por usinas hidrelétricas de maior potência de geração (UHEs > $30 \mathrm{MW}$ ) e com presença de extensos reservatórios.

Se avaliarmos o potencial de impacto do total de 169 barragens em nível de bacia hidrográfica como determina a lei (BRASIL 1986; BRASIL 1997a), podemos antever um cenário de profunda alteração dos pulsos de inundação de cada rio barrado e, por conseguinte, do sistema BAP/Pantanal como um todo. Já há evidente alteração do pulso de inundação natural nos rios com usinas hidrelétricas e seus grandes reservatórios já instalados nos rios Manso, Casca, São Lourenço (considerada uma PCH com 29,1 MW, mas que apresenta um grande reservatório de cerca de 20 km de extensão), Itiquira e Correntes, todos tributários da principal subbacia do sistema BAP/Pantanal, a bacia do rio Cuiabá, sendo que o próprio rio Cuiabá também apresenta alteração no pulso de inundação pelo conjunto de barragens já em operação na bacia.

Contudo, até o momento, a alteração do pulso de inundação no rio Cuiabá foi pesquisada apenas com relação à influência da barragem de Manso, tendo sido observada a redução na vazão durante o começo das chuvas em cerca de $20 \%$ e aumento na fase de seca, resultando em elevação do nível em cerca de $1 \mathrm{~m}$ (ZEILHOFER; MAURO, 2009). Tais alterações apresentam implicações ecológicas e, por conseguinte, socioeconômicas, como a diminuição observada no desembarque pesqueiro em Cuiabá (CATELLA, 2001) e a diminuição de área de pastagens na fase de seca em comunidades tradicionais ribeirinhas como as da localidade de Mimoso. Outros rios, como Juba e Jauru, em Mato Grosso, também já estão com vazões e periodicidade de cheias e secas modificadas devido ao efeito do barramento e dos grandes reservatórios das respectivas usinas hidrelétricas. Onde há UHEs com grandes reservatórios essas variações deixam de ser sazonais e passam a ser diárias como reportado no vídeo $O$ dia em que o rio secou.

Há riscos elevados de que o mesmo fenômeno ocorra em outros rios formadores do Pantanal, onde há a previsão de construção de 3 UHEs e/ou de sequências de PCHs que totalizam os 124 empreendimentos ainda previstos, o que afetará o pulso de inundação de cada rio barrado, individualmente, e com elevada possibilidade de potencializar os efeitos sinérgicos de todos do conjunto de 169 barramentos, afetando o pulso de inundação do Pantanal.

Em toda a bacia, são oito as usinas hidrelétricas de grande porte (Casca III, Manso, Jauru, Juba I, Juba II, Itiquira I, Itiquira II, Ponte de Pedra), sendo que cinco delas já foram construídas nos maiores afluentes da principal sub-bacia - a bacia do rio Cuiabá, responsável por $40 \%$ da água de todo o sistema BAP/Pantanal (figura 2).

As UHEs já construídas representavam em 2010 (MPF 2010), segundo o Diretor de Estudos Ambientais da Empresa de Pesquisa Energética (EPE), o "filet mignon" do aproveitamento energético potencial da bacia. Os demais projetos, no caso as PCHs e as Centrais Geradoras de Hidroeletricidade (geração de energia com potencial < $1 \mathrm{MW}$, mas recentemente aumentada para até $5 \mathrm{MW}$ (ANEEL 2018), agregariam muito pouco ao total de energia gerada no país.

A energia gerada pelos empreendimentos em operação em 2010 (8 UHEs e 21 PCHs = 29 barragens) representavam cerca de $70 \%$ do potencial de geração total de energia hidrelétrica da BAP e esse total (1.620 $\mathrm{MW}$ ) representava apenas $2,1 \%$ do total da energia hidrelétrica gerada no país (77.281 MW) (MPF 2010). 


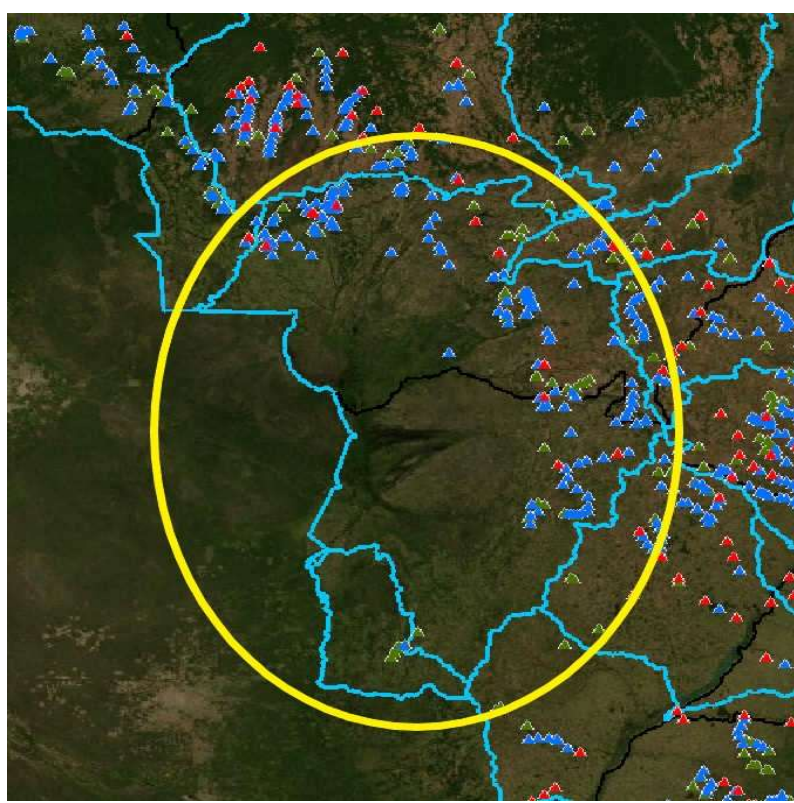

Figura 2 - Localização das 169 hidrelétricas (triângulos), atuais e previstas na Bacia do Alto Paraguai (delimitada em amarelo), sendo UHEs (em vermelho), PCHs ( em azul) e CGHs (em verde). Fonte: ANEEL (2018).

Segundo a Agência Nacional de Energia Elétrica (Aneel) (BRASIL, 2016), o total de energia hidrelétrica gerada no país passou a 92.195 MW e estima-se que o da BAP tenha crescido para $2.140 \mathrm{MW}$, o que mantém a participação da bacia em apenas 2,3\%. Em relação ao total de todas as fontes de geração de energia elétrica (incluindo a térmica, solar e eólica $=142.179 \mathrm{MW}$ ) a participação da energia elétrica gerada na BAP cai para cerca de 1,5\%; porém 75\% da água do sistema BAP/Pantanal é proveniente da região norte da bacia, do Mato Grosso e o norte de Mato Grosso do Sul (sub-bacia do rio Taquari, formada pelos rios Coxim, Jauru, Ariranha e Taquari - com previsão de 28 PCHs e 2 UHEs). Nessa região, o desnível entre planalto e planície é maior e, por conseguinte, com maior potencial hidráulico, o que leva à concentração da maioria (96\%) dos empreendimentos atuais e dos previstos (88\%), o que representa $91 \%$ do total dos empreendimentos (em operação e previstos). Assim, com a construção dos 124 empreendimentos planejados, a maioria dos principais rios do norte da bacia ficaria barrada, com elevado potencial de alterar o pulso de inundação no Pantanal Sul.

Em contrapartida, a BAP naturalmente apresenta um alto potencial erosivo, com elevada produção de sedimentos (CARVALHO et al., 2008; SILVA et al., 2011; SOUZA, 2013), dada à predominância de arenitos, mas que têm sido potencializados pelo mau uso do solo no planalto nas extensas áreas ocupadas por atividades agrícolas fortemente mecanizadas e de culturas anuais (grãos e algodão) e em especial pela pecuária. A pecuária, geralmente implantada em solos mais frágeis, quando mal feita, é responsável por elevado nível de degradação de pastagens, promovendo processos erosivos como voçorocas (GALDINO et al., 2005).

Cabe salientar que desde 1994 a supressão da vegetação nativa no bioma tem aumentado, passando de 5\% para 12\% em 2008 (SILVA et al., 2011), alcançou 15\% em 2014 (MONITORAMENTO 2015) e 18\% em 2016 (WWF 2017). Recentemente, o Pantanal da Baixada Cuiabana foi considerado pelo setor agrícola (APROSOJA) como a nova fronteira para a produção de grãos. No planalto circundante à planície, a situação é mais grave, sendo que apresentava $46 \%$ de perda de cobertura vegetal nativa em 1994, passando a $59 \%$ em 
2008 (SILVA et al., 2011) e 60,5\% em 2014, sendo que algumas regiões de cabeceira, em especial no noroeste da bacia, apresentam 80\% de perda de vegetação natural (MONITORAMENTO 2015). O mau uso do solo e os processos erosivos promovem o assoreamento dos rios, como pode ser observado em maior ou menor magnitude.

Os impactos do assoreamento são problemas também para a geração de energia, como apontado por diversos autores (CAMPAGNOLI, 2005; CARVALHO et al., 2008), referindo-se à perda de volume útil e da capacidade de regularização dos reservatórios, bem como ao desgaste das turbinas por abrasão física causada por areias e abrasão química causada pela má qualidade da água, induzindo a gastos adicionais com a manutenção, incluindo também operações de dragagem nas proximidades da tomada d'água para as turbinas.

Barrando-se o fluxo natural de água, nutrientes, sedimentos e organismos, coloca-se em risco a conservação da saúde ambiental do Pantanal. Por meio desse processo, ficará comprometida a conservação dos processos geomorfológicos (dinâmica natural de sedimentos provenientes do planalto) e ecológicos que regem o sistema, sua biodiversidade e os benefícios (serviços ambientais) que oferece à sociedade pantaneira e brasileira como água em quantidade e qualidade. Da mesma forma, serão afetadas a pesca e a pecuária tradicional (com cerca de três milhões de cabeças), em sua grande maioria produzidas em pastagem nativa em que o pulso de inundação tem papel fundamental para fertilizar o solo e renovar as pastagens, a chamada "limpeza do pasto" -, além de garantir a segurança alimentar de povos e comunidades tradicionais, bem como das populações socialmente vulneráveis das áreas urbanas nas cidades pantaneiras e peri-pantaneiras, com oferta de peixes como alimento farto e altamente nutritivo.

\section{Impactos Socioeconômicos na Pesca}

Em 2012, em uma avaliação preliminar, foram entrevistados os presidentes das Federações de Pescadores de Mato Grosso e de Mato Grosso do Sul para fornecer dados relacionados à atividade de pesca profissional na bacia do Alto Paraguai quanto ao número de pescadores profissionais-artesanais e qual seria a maior e a menor renda obtidas durante a temporada de pesca que vai de março a outubro. Durante quatro meses (novembro a fevereiro), há a proibição da atividade de pesca, pois é a época do deslocamento dos cardumes das espécies de peixes migratórios rio acima para a reprodução na região de cabeceiras, denominada "época do defeso", e o rendimento dos pescadores passa a ser de apenas um salário mínimo por meio do pagamento do Seguro Desemprego. Foram também entrevistados os presidentes das associações de turismo de pesca de duas cidades pantaneiras, Cáceres (MT) e Corumbá (MS), sobre o número de barcos hotéis, número de empregos diretos e indiretos gerados pela atividade, e o rendimento na alta e na baixa temporada; no período de defeso, a atividade tem rendimento zero.

O resultado foi surpreendente, levando-se em conta que foram avaliadas apenas duas cidades, das 21 cidades pantaneiras e peri-pantaneiras, ou das 15 em que a pesca profissional e turística tem importância social e econômica expressiva, sendo fundamentais para a geração de emprego e renda como nos municípios de Barra do Bugres, Cáceres, Poconé, Cuiabá, Várzea Grande, Santo Antônio do Leverger, Barão de Melgaço, 
Rondonópolis (Mato Grosso) e Coxim, Miranda, Aquidauana, Anastácio, Corumbá, Ladário e Porto Murtinho (Mato Grosso do Sul). Coxim, por exemplo, tem sua economia dependente da pesca, como pode ser constatado pelos depoimentos do Prefeito do Município de Coxim (MS), do Presidente da Federação de Pescadores de Mato Grosso do Sul e dos próprios pescadores de Coxim (MS), no vídeo $O$ dia em que o rio secou.

Em Mato Grosso, em 2012, havia oito colônias de pescadores profissionais na BAP, que contavam aproximadamente 6.000 famílias. Segundo o representante da Federação de Pescadores, o rendimento varia de forma sazonal (varia com o pulso de inundação) e por região (planalto x planície), sendo de 1 salário e meio (aproximadamente $\mathrm{R} \$ 900,00$ ) até 3 a 4 salários (por volta de $\mathrm{R} \$ 2.500,00$ ) e de $\mathrm{R} \$ \mathbf{6 2 2 , 0 0}$ no defeso (salário mínimo à época). Em Mato Grosso do Sul, eram seis colônias de pescadores profissionais na bacia, com cerca de 3.500 famílias e um rendimento estimado na mesma ordem de grandeza, segundo o Presidente da Federação. Assim, tem-se um total de 10.000 famílias com renda de, no mínimo, R\$ 9 milhões/mês ou R\$ 72 milhões por oito meses no ano (excetuando-se os quatro meses de defeso), em 2012.

Dados do Sistema de Controle da Pesca de Mato Grosso do Sul (SCPESCA/MS) no mesmo ano de 2012, relacionados aos dados obtidos do pescado capturado em toda a Bacia do Alto Paraguai no estado e vistoriado pela Polícia Militar Ambiental/MS, contabilizaram um total de $338 \mathrm{t}$ de pescado, das quais $173 \mathrm{t}(51 \%)$ pela pesca profissional e $165 \mathrm{t}$ (49\%) pela pesca esportiva. As espécies mais capturadas pelas duas categorias juntas foram: cachara (Pseudoplatystoma reticulatum) (70 t, 21\%), pintado (Pseudoplatystoma corruscans) (65 t, 19\%), e pacu (Piaractus mesopotamicus) (38 t, $11 \%$ ).

Os rios que mais contribuíram foram o rio Paraguai (143 t, 43\%) e o rio Miranda (130 t, 39\%). Segundo o SCPESCA de 2012, o número total de pescadores profissionais registrados foi de 2.248 e o de pescadores esportivos foi de 14.044. Observa-se, todavia, uma discrepância expressiva entre o número de pescadores profissionais apresentados no SCPESCA (ALBUQUERQUE et al., 2013) e os informados pela Federação. Cabe salientar que as espécies de peixes mais rentáveis economicamente para os pescadores profissionais, mais atrativas para a pesca turística e de maior valor cultural são justamente as migratórias como o cachara, pintado, pacu, dourado, jaú, etc.

Quanto à pesca turística, em entrevista, o responsável pela Associação de Empresas de Turismo de Pesca de Cáceres (MT), declarou que na cadeia da atividade turística que envolve agências, transporte, restaurantes e serviços de alimentos, meios de hospedagem (pousadas, hotéis, barcos-hotéis), fornecedores de insumos, materiais e combustíveis, construção e manutenção da infraestrutura e dos serviços eram gerados, segundo estimativa, aproximadamente 1.000 empregos diretos e 3.000 indiretos, totalizando 4.000 empregos. A remuneração dos funcionários variava entre $R \$ 1.200$ e 3.000 , o que resulta em $R \$ 14,4$ milhões/ano, no mínimo, relacionado apenas aos empregos diretos. O rendimento das empresas foi estimado na ordem de cerca de R\$ 6 milhões/ano (sendo 90\% para investimento na própria atividade e 10\% de lucro). Em Corumbá (MS), segundo o responsável pela Associação Corumbaense das Empresas Regionais de Turismo (ACERT) havia uma geração de 7.600 empregos diretos e 10.000 indiretos, totalizando 17.600 empregos. A remuneração dos funcionários variava entre $\mathrm{R} \$ 900$ a 3.000, o que resulta em, no mínimo, cerca de $\mathrm{R} \$ \mathbf{8 2 , 1}$ 
milhões/ano. O rendimento das empresas foi estimado em cerca de $\mathrm{R} \$ 10$ milhões/ano (sendo também aplicados $90 \%$ como investimento no próprio negócio e obtendo $10 \%$ de lucro).

No total, em apenas duas cidades pantaneiras, existe uma remuneração para o turismo de pesca de, no mínimo, R\$ 96,5 milhões/ano, apenas levando em consideração os cerca de 9.000 empregos diretos. Se esses valores forem somados aos $\mathrm{R} \$ 72$ milhões/ano resultante da pesca profissional nos dois estados, calcula-se cerca de $\mathrm{R} \$ 169$ milhões/ano. Como exercício econômico, se fosse multiplicada a média da renda relacionada apenas aos empregos diretos das duas cidades ( $R \$ 2.000,00 \times 12$ meses $x$ estimativa de 2.000 empregos diretos) para o total das 15 cidades da região, que têm alguma porcentagem de sua economia baseada na pesca (profissional e turística), manifesta-se um potencial de geração de renda de cerca de R\$ 720 milhões/ano. Somando-se ao rendimento dos pescadores profissionais, totalizam R\$ 792 milhões/ano.

Ainda merecem ser levado em conta os rendimentos dos empresários de turismo de pesca, estimados (SHRESTHA et al., 2002) como da ordem de US\$ 35-56 milhões (R\$ 124-198 milhões, na cotação atual), sendo que avaliaram apenas duas cidades (Corumbá e Miranda, em Mato Grosso do Sul). Além do turismo de pesca, os valores movimentados pelas atividades de turismo ecológico, de aventura, cultural, rural, etc., bem como da pecuária extensiva tradicional (que historicamente conserva a paisagem natural e a produção do gado é feita com base nas pastagens nativas), com certeza seriam agregados mais alguns bilhões/ano.

Seidl e Moraes (2000) avaliaram os serviços ambientais globais do Pantanal (região da Nhecolândia) como sendo da ordem de US\$ 15 bilhões anuais, levando em consideração um valor de US\$ 5.840,00/ha/ano. Já Moraes (2008) estimou o valor econômico total do Pantanal e encontrou que a região contribui com aproximadamente US\$10.100,00/ha para o bem-estar do planeta. De forma inovadora, como alternativa economicamente viável para se tentar conservar a região, o autor sugere que se crie um fundo global para comprar dos pecuaristas o direito de alterar a paisagem natural de suas terras, o que compensaria os produtores por sua adesão aos objetivos globais de conservação; todavia, mantendo os demais direitos de posse da terra, inclusive quanto às formas de manejo extensivo.

Dessa forma, segundo os estudos disponíveis de valoração econômica, já se pode estimar que os serviços ecossistêmicos do Pantanal saudável seriam da ordem de bilhões de dólares, montante que fornece subsídios para contrapor os ganhos auferidos pela geração de energia elétrica que são, em geral, concentradores de renda, estão em poder de corporações e desestabilizam as atividades econômicas preexistentes por seu uso exclusivista e potencialmente comprometedor.

A base da economia de alguns municípios pantaneiros estaria, portanto, fortemente ameaçada pelo potencial aumento da perda de produção pesqueira nos principais rios da região, um serviço ecossistêmico fundamental que o Pantanal saudável oferece para a economia local e regional, e que não está sendo considerado de forma efetiva pelas instâncias decisórias.

Como comentado anteriormente, os ciclos de cheias e secas influenciam as relações sociais, culturais e econômicas da população pantaneira e sustentam as atividades econômicas tradicionais da região, a qualidade de vida das suas comunidades ribeirinhas e tradicionais, sua segurança alimentar, bem como das populações mais pobres das áreas urbanas, que dependem da saúde ambiental do bioma. A manutenção do 
funcionamento hidro ecológico natural do sistema BAP/Pantanal resulta na conservação dos serviços ambientais de que os pantaneiros usufruem, como o acesso à água em quantidade e qualidade, oferta de alimentos de qualidade como os peixes, acesso à biodiversidade vegetal - como a oferta e renovação das pastagens nativas, plantas medicinais, fibras, etc. No entanto, o volume de água, sua vazão, a área inundada e a periodicidade das inundações de cada rio formador do Pantanal e, por conseguinte, do pulso de inundação de todo o sistema, tem elevado potencial de alteração devido à proliferação dessas centenas de barragens previstas para a geração de energia hidrelétrica na área de transição planalto-planície pantaneira.

A socioeconomia regional ligada à pesca já está sendo afetada de forma negativa, em especial nas bacias dos rios Jauru, Juba, Cuiabá, São Lourenço, Itiquira e Correntes, sem que qualquer controle ou planejamento em nível de bacia hidrográfica, em relação aos efeitos conjuntos e sinérgicos de todos os empreendimentos (em operação e previstos) esteja sendo colocado em prática de forma efetiva. Além disso, somam-se os impactos do assoreamento dos rios e da contaminação por agrotóxicos resultantes da atividade agropecuária no planalto, que também afetam a produção pesqueira pela alteração, respectivamente, na hidrodinâmica e perda de habitats, e por comprometer o potencial biótico dos organismos aquáticos, incluindo os peixes.

\section{Interesses Econômicos na Exploração Hidrelétrica da BAP}

Existem interesses econômicos para a exploração da energia hidrelétrica, devido à sua alta atratividade em termos de lucros financeiros, sendo que a construção e a operação de PCHs no Brasil podem ser consideradas investimentos com alta rentabilidade. A concessão do uso dos recursos hídricos é de 30 anos e, em média, em cinco anos, os empreendedores quitam seu investimento, muitas vezes financiados por empréstimos subsidiados de bancos públicos, em especial o BNDES, e passam a ter, portanto, 25 anos de lucro garantido uma vez que a energia gerada é totalmente comercializada ao entrar no Sistema Interligado Nacional (SIN), gerenciado pelo Operador Nacional do Setor Elétrico (ONS), sendo disponibilizada para todo o país. Além disso, segundo exposição do Prof. Dr. Dorival Gonçalves Jr. (Engenharia Elétrica/UFMT), as PCHs têm um processo de licenciamento mais simplificado e que muitas vezes dispensa o Estudo de Impacto Ambiental (EIA).

Em contrapartida, embora a faixa que vai da região Centro-Oeste até a região Nordeste, atravessando a BAP e o país de forma transversal, seja uma das que mais apresentam potencial para a utilização de energia solar, por apresentar elevados índices de radiação solar em todo ano (PEREIRA et al., 2006), praticamente não é utilizada. Utiliza-se, no Brasil, menos energia solar do que países de clima temperado como Alemanha ou Japão (BP 2016). Para Christopher Flavin, do Worldwatch Institute, especialista mundial em energia renovável, a dinâmica do mundo está mudando rapidamente e o Brasil precisaria começar a considerar tecnologias e políticas mais avançadas. O Brasil, segundo Flavin (2011), tem recursos significativos de energia eólica e solar, pois tem energia solar de boa qualidade em praticamente todos os lugares, inclusive nas áreas de maior concentração da população; contudo, observa que, se as políticas públicas não forem adequadas, essas fontes não serão implementadas (BOLETIM ENERGIA, 2011). 
Atualmente, o governo e o mercado têm sinalizado maior interesse pelas energias alternativas, com o crescimento da geração eólica e os recentes leilões de energia fotovoltaica. Em outubro de 2014, houve o primeiro leilão de energia solar no país, seguido de outros em 2015 (EPE 2015). O aproveitamento de energias alternativas, incluindo a geração por biomassa no país, de certa forma, aliviaria, indiretamente, a pressão por novas hidrelétricas, em especial as PCHs com menor capacidade de geração, mantendo, portanto, mais rios livres de barragens no país e também na bacia do Alto Paraguai. Contudo, não necessariamente seriam alternativas à continuidade de implantação de empreendimentos hidrelétricos, já que a tendência seria utilizar todas as opções de matrizes energéticas, dada a avidez de um setor altamente lucrativo.

No total, a capacidade instalada de energia solar no Brasil em fevereiro de 2016 foi de cerca de 23 MW apenas, número que deve crescer para 929 MW já em 2018 (BRASIL 2016). Segundo Carolina Reis, especialista do setor de energia fotovoltaica, trata-se de um mercado em franca expansão, com potencial aproveitado de apenas $0,01 \%$ no país e com previsão de crescimento de $8.000 \mathrm{MW}$ até 2024 . Além disso, com a mudança nos padrões climáticos e uma economia cada vez mais eletro intensiva, as hidrelétricas não serão suficientes para abastecer o país todo. Ainda de acordo com Reis, o ponto chave de qualquer matriz energética é a diversificação. Assim, o país precisa investir em todas as fontes de energia renovável e há a lacuna da energia solar na nossa matriz (CONEXÃO PLANETA 2016).

Contudo, em uma publicação do setor elétrico (BOLETIM ENERGIA 2015), Alexandre Uhlig, técnico do setor empresarial, afirma que o país ainda dispõe de um grande potencial hidrelétrico a ser explorado e é importante que os melhores aproveitamentos hidráulicos sejam desenvolvidos, mas a previsão é que, a partir de 2030, restem poucos aproveitamentos viáveis ainda por explorar. Portanto, segundo ele, seria necessário recorrer a outras fontes para atender ao crescimento da demanda por energia elétrica, já utilizando, inclusive, a expressão Expansão da geração na era pós-hidrelétrica. A participação hídrica, antes quase total na geração de energia do país, caiu a $80 \%$ e pode ir a $60 \%$ até 2035 , sobretudo quando se considera o possível esgotamento do potencial de geração hidrelétrica.

Ainda segundo técnicos do setor (SALES; UHLIG 2015), em 2014, as hidrelétricas representavam 67\% da capacidade instalada para gerar eletricidade no Brasil. Quarenta por cento de todo o potencial hidráulico foi explorado e até 2023 o planejamento oficial prevê a exploração de 14,7 GW adicionais, aumentando o potencial explorado para 46\%. A exploração do restante do potencial hidráulico, cuja grande parte encontrase na Amazônia, já tem sido limitada por uma série de razões, incluindo preocupações com povos indígenas e com áreas protegidas (unidades de conservação) existentes na região. Pelo łado viés governamental, o Secretário de Planejamento e Desenvolvimento Energético do Ministério de Minas e Energia, Altino Ventura Filho (BOLETIM ENERGIA 2015), afirma que o Brasil criou dificuldades para a exploração hidrelétrica de áreas próximas ou internas a reservas indígenas, de proteção permanente e parques nacionais: "Estamos abrindo mão de 80 mil MW, e nenhum país do mundo faz isso com energia renovável"; ou seja, para o setor elétrico, tanto empresarial quanto governamental, dever-se-ia mudar a Constituição brasileira e explorar esses potenciais. Tal situação geraria grandes impactos socioambientais ao território e às populações nativas da Amazônia. 
Conforme as perspectivas e desafios avaliados pelo setor elétrico, devido ao aumento da influência da sociedade civil, a expectativa é de encarecimento do custo da energia e de maiores dificuldades para ampliação e manutenção do sistema interligado. Isto se daria pela intensificação da participação da sociedade no processo decisório, gerando aumento nos prazos de licenciamento e maior dificuldade para aprovação de novos projetos e, por conseguinte, elevando o tempo para aprovação e o custo de novos empreendimentos de energia (BOLETIM ENERGIA 2011). Para o setor elétrico, o aumento da influência da sociedade civil, devido à maior participação no processo decisório, bases para o amplo exercício da democracia, e recomendadas pela Agenda 21 (2004) e pela própria World Comission on Dams (WCD 2000), são interpretadas como perspectivas negativas para o empresariado ligado ao setor elétrico brasileiro.

De acordo com o Prof. Ildo Sauer IEE/USP (BOLETIM ENERGIA 2015), o potencial de geração solar é infinito: bastaria um quadrilátero de $90 \times 90 \mathrm{~km}$ para se gerar volume de energia suficiente para atender ao consumo no Brasil hoje. Sauer entende que o futuro do Brasil é hidro-eólico, com complementação térmica, como se tem feito hoje. Afirma também que o potencial eólico é muito maior do que aponta o atlas eólico, cuja última versão é de 2001, isso porque hoje as torres são de 100, 120 metros de altura, maiores do que no inventário. Ele ainda aposta na geração solar, mas criticou a contratação desta energia de forma centralizada: "Temos o recurso bem distribuído por todo o país, o que permite gerar perto do ponto do consumo, sem ter que pagar transmissão e distribuição". Em finais de 2015, os empreendimentos solares contratados somaram uma potência de 929,3 MW para uma garantia física de 262,0 MW médios, localizados na Bahia, Ceará, Minas Gerais, Pernambuco, Rio Grande do Norte, São Paulo e Tocantins (INSTITUTO ACENDE BRASIL 2015).

\section{RESULTADOS E DISCUSSÃO}

Os processos de assoreamento são evidentes na bacia do Alto Paraguai e com inúmeros focos de erosão expressivos, sendo os projetos de recuperação praticamente inexistentes, tornando significativamente menor o tempo de vida útil dos reservatórios e resultando em menor lucratividade para o setor; há registros de dragagem nos reservatórios do Sistema Itiquira por duas vezes, a um custo provavelmente elevado. Assim, mesmo com empecilhos como a elevada taxa de assoreamento dos reservatórios, com a possibilidade de mudanças climáticas afetarem a produção de energia hidrelétrica, em especial a das PCHs na fase de seca, o potencial de exploração de energia hidrelétrica na BAP tem crescido consideravelmente.

De acordo com Calheiros et al. (2012), os prognósticos quanto à conservação do pulso de inundação natural de cada rio (variação de nível, vazão, área e periodicidade das inundações) e, por conseguinte, dos serviços ecossistêmicos de todo o sistema BAP/Pantanal, são preocupantes. Nesses últimos 15 anos, houve uma intensa proliferação de barragens para a produção de energia hidrelétrica na bacia. $O$ primeiro represamento de maior porte ocorreu em 1999, em um tributário do rio Cuiabá, o rio Manso, sendo duramente criticado por pesquisadores e pela sociedade civil à época, por estar localizado na principal bacia do sistema Pantanal, com um grande reservatório $\left(427 \mathrm{~km}^{2}\right)$, sem ainda sequer ter indenizado devidamente a população atingida, tanto a montante quanto a jusante do reservatório embora tivesse sido prevista (WERNER Jr et al., 2003; FGV, 2014). A partir daí, o número de hidrelétricas aumentou significativamente, 
provocando grande impacto ambiental e pouca contribuição para a geração de energia, comparado com as grandes regiões produtoras do Brasil.

Segundo Bermann (2016), no Brasil os investimentos na ampliação da oferta energética estão alinhados com a demanda prevista em relação ao crescimento econômico, o Produto Interno Bruto - PIB, que, em geral, é superdimensionada. As políticas desenvolvidas ao setor de energia acabam possibilitando que os interesses empresariais sobressaiam-se frente aos interesses da sociedade e não são pautadas ainda na falta de eficiência energética. A inclusão do uso de bagaço de cana no rol de fontes renováveis, por exemplo, poderia já aportar cerca de $5.000 \mathrm{MW}$ no SIN. Em contrapartida, a possibilidade de se promover a repotencialização (uso de tecnologias atuais e bem mais eficientes) das já obsoletas caldeiras das usinas produtoras de açúcar e álcool como também de grande parte das turbinas das hidrelétricas aumentaria significativamente a oferta de energia. Seria necessário, então, para Bermann (2011), redefinir a política energética e isso só será possível com o envolvimento da sociedade. O Conselho Nacional de Política Energética não conta entre seus membros, como é determinado em sua criação, com representantes da academia e da sociedade civil. Esse distanciamento entre o conhecimento científico e as decisões políticas faz prevalecer os interesses empresariais imiscuídos no governo como interesses públicos.

Em 2002 existiam nove empreendimentos em operação e 22 previstos (GIRARD 2002). Sete anos depois, em 2009, esses números ampliaram-se para 116 projetos, sendo 29 em operação e 87 sob licenciamento ou previstos (CALHEIROS et al., 2009; CALHEIROS, 2010; CALHEIROS; OLIVEIRA, 2010). Em 2012, o número total de empreendimentos chegou a 135, sendo 44 em operação e 91 previstos (CALHEIROS et al., 2012). Atualmente, o total de empreendimentos chegou a 169 barragens, entre atuais e previstas, crescimento de mais de $500 \%$ em 15 anos. Desse total, $86 \%$ correspondem a pequenas centrais hidrelétricas ( $\mathrm{PCHs})$, consideradas como fontes de "energia limpa" pelo setor elétrico, mas que são construídas em áreas fundamentais para a desova de peixes, como as cabeceiras dos rios, e geram pouca energia, além de que também não contribuírem para a geração durante a fase crítica de seca.

A BAP é relativamente bem analisada inclusive com estudos governamentais importantes como o Estudo de Desenvolvimento Integrado da Bacia do Alto Paraguai - EDIBAP (Brasil 1981), o Plano de Conservação da Bacia do Alto Paraguai - PCBAP (BRASIL 1997b), e o Projeto GEF Pantanal/Alto Paraguai (BRASIL 2003). Todos estes estudos apontam para uma mesma direção: a necessidade de mecanismos especiais de gestão, em face das fragilidades dos ecossistemas da região e a dependência social em relação à saúde ambiental.

A gestão da BAP deveria ser embasada no que se denomina como gestão ecossistêmica de recursos hídricos, não apenas a gestão puramente hidrológica como costumeiramente se fez no país, com base apenas nas vazões mínimas estanques $\left(Q_{7,10}\right.$ - vazões mínimas de sete dias consecutivos e período de retorno de 10 anos ou $Q_{95}$ - vazões maiores ou iguais a um determinado valor durante 95\% do tempo) (SILVEIRA et al., 2006; COLLISCHONN et al., 2005) sem levar em conta a variação sazonal.

Segundo Postel e Richter (2003) e Collischonn et al. (2005), a gestão de recursos hídricos deve também ser feita de forma participativa, tendo como base um profundo diagnóstico das características 
hidrológicas, ecológicas e socioeconômicas e na totalidade da bacia hidrográfica, exatamente como determinava a Lei das Águas ainda em 1997 (Brasil 1997a). Afinal, segundo a Constituição Federal (BRASIL 1988), "para assegurar a efetividade do direito ao meio ambiente ecologicamente equilibrado, bem de uso comum do povo e essencial à sadia qualidade de vida incumbe ao Poder Público: preservar e restaurar os processos ecológicos essenciais e prover o manejo ecológico das espécies e ecossistemas".

O respeito à dinâmica natural das vazões, à garantia de acesso aos recursos naturais que suportam os usos tradicionais da bacia e à vocação natural da socioeconomia local, ou seja, o respeito aos usos múltiplos, é fundamental viabilizar a produção de energia e os demais aproveitamentos econômicos dos recursos naturais da região, garantindo a conservação ambiental. Contudo nenhum desses estudos previu o problema do aumento de hidrelétricas na BAP em tal magnitude, exceto o GEF/Pantanal (BRASIL 2003), que menciona a questão muito superficialmente, citando apenas quatro hidrelétricas e colocando como causa primária de impactos, não as barragens propriamente ditas e/ou o efeito sinérgico do conjunto, mas apenas a "operação inadequada" de UHEs e a alteração do regime hidrológico, embora as classificando como uma tendência "crescente".

No caso da avaliação sobre a perda da biodiversidade, mencionam várias causas pertinentes aos barramentos, mas sem relacioná-los diretamente como o motivo real ou potencial, como: alteração do regime hidrológico, fragmentação de habitats, projetos inadequados de obras de infraestrutura, alteração da qualidade da água, obstáculos à migração de espécies de peixes, alteração no ciclo sazonal de nutrientes e na cadeia trófica, perda de habitats naturais e de espécies nativas; a maioria apresentando a categoria de "crescente", exceto no tema Projetos inadequados de obras de infraestrutura, que ironicamente está classificado como de tendência "decrescente". Citam ainda como o estopim da problemática ambiental na bacia uma Limitada consciência política e de cidadania; ou seja, os órgãos públicos não consideraram devidamente o fato de que no futuro a BAP seria alvo de tamanha exploração do seu potencial hidroenergético, e não houve, por conseguinte, um planejamento sobre os impactos socioambientais da proliferação de barramentos na bacia.

Por seu valor em termos de área úmida de importância internacional, segundo a Convenção Ramsar (RAMSAR 2016), como Patrimônio Nacional (BRASIL 1988), como Patrimônio Natural da Humanidade e Reserva da Biosfera (UNESCO 2000a,b) e por sua fragilidade, o Pantanal deveria demandar um cuidado especial para se alcançar o desenvolvimento realmente sustentável da região (ALHO, 1988; ALHO, 2011ab; DA SILVA, 2000; HAMILTON, 2002; NUNES DA CUNHA, 2005; MORAES, 2008; CALHEIROS et al., 2009; 2012).

Com a proposição do Plano Nacional de Recursos Hídricos - PNRH (BRASIL 2006b) e dos Planos Estaduais de Mato Grosso (PERH-MT) e do Mato Grosso do Sul (PERH-MS), bem como o Relatório do Projeto GEF/Pantanal (BRASIL 2003) avaliou-se que haveria, enfim, a oportunidade de viabilizar a implementação de ações para a gestão integrada da região, previstas no PCBAP (Brasil 1997b). Entretanto, pouco se avançou dando continuidade ao quadro progressivo e preocupante de degradação ambiental e mau uso dos recursos naturais como, por exemplo, os elevados níveis de desmatamento no planalto, em conjunto com o aumento expressivo de barramentos, ampliando a degradação ambiental e, consequentemente, a necessidade cada 
vez maior de recursos financeiros para a recuperação dos danos provocados (BRASIL 2006a) provocando uma lógica negativa perversa.

Porém, pela intervenção ativa da sociedade civil organizada da região desde 2009, em especial a Rede Pantanal de ONGs e Movimentos Sociais e o FONASC - Fórum Nacional da Sociedade Civil nos Comitês de Bacias Hidrográficas, em conjunto com a participação individual de pesquisadores da Embrapa Pantanal, UFMT e UNEMAT, o Conselho Nacional de Recursos Hídricos - CNRH passou a discutir em várias de suas Câmaras Técnicas as recomendações resultantes de um workshop internacional (CALHEIROS et al., 2009) sobre a conservação da região. Dessas ações, aprovou-se, por fim, a Resolução CNRH no 152/2013 (BRASIL, 2013), com força de lei, para a elaboração de um Plano de Bacia, ou Plano de Recursos Hídricos da Região Hidrográfica do Alto Paraguai, mesmo a BAP não possuindo ainda um Comitê de Bacia Hidrográfica instalado.

A proposta de elaboração desse Plano de Recursos Hídricos, coordenado pela Agência Nacional de Águas - ANA, é um avanço importante, caso seja bem-sucedido, pois é uma forma de se promover alguma forma de planejamento para a região em nível de bacia hidrográfica, não mais com base em ações diferenciadas em cada estado em separado, especialmente no que se refere à contraposição entre proliferação de barramentos e a conservação da produção pesqueira, com o intuito de garantir o respeito aos Usos Múltiplos das Águas, previstos na Lei de Recursos Hídricos no 9.433/1997 (BRASIL, 1997a), bem como a conservação do Pantanal prevista em nossa Carta Magna.

Desta forma, vislumbra-se um cenário um pouco mais alentador no que se refere à aplicação dos princípios da Prevenção e Precaução quanto ao elevado potencial do conjunto desses empreendimentos hidrelétricos, em associação aos demais impactos, de alterar ainda mais o regime de inundações sazonais e interanuais, afetando a hidrodinâmica natural da planície pantaneira e ameaçando, inclusive, os processos hidro ecológicos essenciais que regem o ecossistema Pantanal, em especial as Unidades de Conservação federais e estaduais da região, os Sítios Ramsar (Parque Nacional do Pantanal Mato-Grossense) e RPPN SESC Pantanal, bem como a parte sul do Pantanal, com implicações sociais potencialmente negativas.

\section{CONCLUSÕES}

Considerando-se que todo o potencial de geração hidrelétrica dos empreendimentos hidrelétricos da Bacia do Alto Paraguai, atuais e previstos, é responsável pela geração de somente 2,3\% de energia hidrelétrica para o país e que cerca de $55 \%$ desse potencial já está instalado e em operação, torna-se extremamente questionável a real necessidade de continuidade de implantação desse modelo exclusivista e excludente de uso dos recursos hídricos, uma vez que não respeita aos demais usuários e coloca em risco a sustentabilidade das principais atividades econômicas da planície pantaneira de elevada importância social, como a pesca e o turismo de pesca, bem como a segurança alimentar de seus povos e comunidades tradicionais. Além disso, é colocada em risco a conservação do Patrimônio Nacional, Patrimônio da Humanidade e Reserva da Biosfera, o Pantanal mato-grossense, que apresenta importância regional, nacional e mundial.

A exploração de outra matriz energética (energia fotovoltaica) em uma das regiões com maior incidência solar do país poderia ser uma alternativa na substituição de implantação de empreendimentos 
hidrelétricos na bacia e respeitaria aos ganhos advindos dos serviços ecossistêmicos proporcionados pelo bioma, que também são elevados e movimentam a economia regional de forma significativa e com expressiva distribuição de renda. No entanto, dada a crescente demanda e alta lucratividade, a avidez do setor empresarial (500\% de aumento no número total de empreendimentos - atuais e previstos - nos últimos 15 anos) manterá a tendência, o que poderá trazer sérios agravos ao Pantanal.

Este estudo propõe que o Estado (Poder Público) e a sociedade brasileira (coletividade) reduzam a exploração hidrelétrica dos rios do Pantanal ainda livres de barragens, uma vez que $55 \%$ de aproveitamento de seu potencial hidrelétrico já podem ser considerados elevados. Dessa forma, seria evitada a continuidade de sua fragmentação, garantindo que Constituição Federal e os direitos da sociedade pantaneira e brasileira sejam respeitados, assim como o bioma. 0 estudo ousa propor um acordo tipo fifty $x$ fifty, ou seja, 50\% para o setor elétrico, $50 \%$ para os demais usos. Destarte o setor energético teria um limite de avanço na apropriação dos recursos hídricos e, ao mesmo tempo, seria garantido o uso social às populações locais.

Nesse sentido, há a necessidade de que haja cooperação e diálogo entre as sociedades civil, comunidade científica, usuários e os tomadores de decisão, potencializando análise isenta em regiões frágeis como a Bacia do Alto Paraguai, formadora da planície pantaneira. Essa parceria deveria garantir a conservação do Pantanal com maior sustentabilidade ambiental, social e econômica, com base no uso racional e múltiplo das águas e dos demais recursos naturais. A informação científica e a legislação contribuem para tal, mas há a necessidade de que as políticas públicas e sua efetivação tomem em conta a realidade social, ecológica e econômica dos povos e comunidades tradicionais, dos pescadores profissionais e/ou artesanais e da sociedade do entorno da BAP.

AGRADECIMENTOS: Agradecemos ao Dr. André Steffens Moraes pesquisador da Embrapa pelas sugestões quanto aos impactos socioeconômicos. O mesmo atuou junto à Embrapa Pantanal entre 1989 e 2012.

\section{REFERÊNCIAS}

AFETADOS pela Usina de Manso, produtores ainda esperam indenização. Escola de Administração de Empresas de São Paulo da Fundação Getúlio Vargas. Centro de Estudos em Sustentabilidade. Diário de Cuiabá, 2014.

AGENDA 21. 2004. Agenda 21 Brasileira: Resultado da Consulta Nacional. Comissão de Políticas de Desenvolvimento Sustentável e da Agenda 21 Nacional. 2a. ed. Brasília: Ministério do Meio Ambiente.

ALBUQUERQUE, S.P.et al. Sistema de Controle da Pesca de Mato Grosso do Sul - SCPESCA/MS 19 - 2012. Boletim de Pesquisa e Desenvolvimento, 124. Corumbá: Embrapa Pantanal, 2013.

ALHO, C.J.R. Biodiversity of the Pantanal: response to seasonal flooding regime and to environmental degradation. Brazilian Journal of Biology, v.68, n.4, 2008. p.957-966.

ALHO, C.J.R.. Biodiversity of the Pantanal: its magnitude, human occupation, environmental threats and challenges for conservation. Brazilian Journal of Biology, v.71, n.1, 2011a. p.229-232.

ALHO, C.J.R.. Concluding remarks: overall impacts on biodiversity and future perspectives for conservation in te Pantanal biome. Brazilian Journal of Biology, v.71, n.1 (suppl.), 2011b. p.337-341.

ALHO, C.J.R.; CAMARGO, G.; FISCHER, E. Terrestrial and aquatic mammals of the Pantanal. Brazilian Journal of Biology, 2011, vol.71, n.1 (suppl.), 2011. p. 297-310.

ANDRADE, M.H.S. Macroinvertebrados bentônicos e o fenômeno da "decoada" (alterações dos parâmetros limnológicos), Pantanal do Rio Paraguai, MS. 2011. 108 f. Tese (Doutorado em Ecologia) - Programa de Pós-Graduação em Ecologia - Instituto de Biociências. Universidade de São Paulo, USP, São Paulo, SP, 2011.

ANDRADE, M.H.S. et al. Spatial and limnological characterization of the Paraguay River floodplain area, 
Southern Pantanal, with emphasis on the "decoada" phenomenon. Geografia, v. 40, número especial, 2015, p. 27-38.

ANEEL. Sistema de Informações Georreferenciadas do Setor Elétrico. Agência Nacional de Energia Elétrica. Ministério de Minas e Energia, 2018.

BASTVIKEN, D. et al. Methane emissions from Pantanal, South America, during the low water season: toward More comprehensive sampling. Environmental Science Technology, v. 44, n. 14, 2010, p. 5450-5455.

BERMANN, C. Qual é o futuro da política energética brasileira? Revista IHU On-line, São

Leopoldo: Instituto Humanitas, 2016.

BOLETIM ENERGIA. Brazil Energy Frontiers: 0 futuro sem fronteiras. n. 13. Instituto Acende Brasil, 2011. BOLETIM ENERGIA. Brazil Energy Frontiers: Frente a frente com o futuro. n. 15. Instituto Acende Brasil, 2015.

BRASIL. Estudos hidrológicos da Bacia do Alto Paraguai: relatório técnico. Departamento Nacional de Obras de Saneamento. Brasília: UNESCO, 1974.

BRASIL. Estudo de Desenvolvimento Integrado da Bacia do Alto Paraguai - EDIBAP. Relatório da Primeira Fase: Descrição Física e Recursos Naturais, t.2. Brasília: SUDECO/PNUD/OEA, 1981.

BRASIL. Resolução do Conselho Nacional do Meio Ambiente. CONAMA no 001, de 23 de janeiro de 1986. Ministério do Meio Ambiente, 1986.

BRASIL. Constituição (1988). Constituição da República Federativa do Brasil de 1988. Brasília, DF, 5 de outubro 1988.

BRASIL. Lei no 9.433, de 8 de janeiro de 1997. Institui a Política Nacional de Recursos Hídricos da Amazônia Legal. Brasília, 08 de janeiro de 1997.

BRASIL. Plano de conservação da Bacia do Alto Paraguai (Pantanal): PCBAP. Análise integrada e prognóstico da bacia do Alto Paraguai. Ministério do Meio Ambiente, dos Recursos Hídricos e da Amazônia Legal. Programa Nacional do Meio Ambiente. Brasília: PNMA, 1997b.

BRASIL. Diagnóstico analítico do Pantanal e Bacia do Alto Paraguai: implementação de práticas de gerenciamento integrado de bacia hidrográfica para o Pantanal e Bacia do Alto Paraguai. Ministério do Meio Ambiente. Brasília: Agência Nacional de Águas - ANA/GEF/PNUMA/OEA, 2003.

BRASIL. Caderno da região hidrográfica do Paraguai. Ministério do Meio Ambiente, Secretaria de Recursos Hídricos. Brasília: MMA. 2006a.

BRASIL. Plano Nacional de Recursos Hídricos. Ministério do Meio Ambiente, Secretaria de Recursos Hídricos. Brasília: MMA. 4v, 2006b. D

BRASIL. Resolução do Conselho Nacional de Recursos Hídricos n. 152, de 17 de dezembro de 2013. Ministério do Meio Ambiente, 2013.
BRASIL. Boletim Mensal de Monitoramento do Sistema Elétrico Brasileiro - Fevereiro 2016. Ministério de Minas e Energia, Secretaria de Energia Elétrica, 2016.

BP. Solar energy. Solar power shows up at scale. British Petroleum, 2016.

CALHEIROS, D.F. Influência do pulso de inundação na composição isotópica $(\delta 13 \mathrm{C}$ e $\delta 15 \mathrm{~N}$ ) das fontes primárias de energia na planície de inundação do rio Paraguai (Pantanal-MS). Tese (Doutorado em Ciências - Universidade de São Paulo, Piracicaba, 2003.

CALHEIROS, D.F.. Importância socioambiental da conservação do pulso de inundação do Pantanal. Corumbá: Embrapa Pantanal. 5p. ADM - Artigo de Divulgação na Mídia, n.139, 2010.

CALHEIROS, D.F. et al. Influência de usinas hidrelétricas no funcionamento hidro ecológico do Pantanal Matogrossense - Recomendações. Corumbá: Embrapa Pantanal. Série Documentos (DOC 102), 2010. 21p.

CALHEIROS, D.F.; HAMILTON, S.K. Limnological conditions associated with natural fish kills in the Pantanal wetland of Brazil. Verhandlungen. Internationale Vereinigung fur Theoretische und Angewandte Limnologie, v.26, 1998. p.2189-2193.

CALHEIROS, D.F.; OLIVEIRA, M.D. O rio Paraguai e sua planície de inundação: o Pantanal mato-grossense. Ciência \& Ambiente, v. 41, 2010. p.113-130.

CALHEIROS, D.F.; OLIVEIRA, M.D.; PADOVANI, C.R. 2012. Hydro-ecological Processes and Anthropogenic Impacts on the Ecosystem Services of the Pantanal Wetland. In: IORIS, A.A.R.. Tropical Wetland Management: The SouthAmerican Pantanal and the International Experience, 2012. Farnham: Ashgate Publishing Ltd.

CALHEIROS, D.F.; SEIDL, A.F.; FERREIRA, C.J.A. Participatory research methods in environmental science: local and scientific knowledge of a limnological phenomenon in the Pantanal wetland of Brazil. Journal of Applied Ecology, v.37, 2000, p.684-696.

CARVALHO, N.O. Hidrologia da Bacia do Alto Paraguai. I Simpósio sobre Recursos Naturais e Socioeconômicos do Pantanal. 1984, Corumbá. Anais... Brasília: Embrapa Pantanal. Série Documentos 5, 1986, p.43-49.

CARVALHO, N.O. et al. Assoreamento dos rios da bacia do Alto Paraguai e do Pantanal e os efeitos decorrentes nas cheias. VIII Encontro de Engenharia de Sedimentos. 1-8 nov. 2008. Anais. UFMS, Campo Grande, MS, 2008.

CAMPAGNOLI, F. Impactos sociais e econômicos da dinâmica sedimentar nos reservatórios hidrelétricos brasileiros. XVI Simpósio Brasileiro de Recursos Hídricos, 2005. Anais. João Pessoa, PB.

CATELLA, AC. A pesca no Pantanal de Mato Grosso do Sul, Brasil: descrição, nível de exploração e manejo (1994 1999). 343p. (Tese Doutorado em Biologia Tropical e Recursos Naturais) - Instituto Nacional de Pesquisas da Amazônia, Universidade do Amazonas, Manaus, 2001. 
CATELLA, A.C.; CAMPOS, F.L.R.; ALBUQUERQUE, S.P. Sistema de Controle da Pesca de Mato Grosso do Sul SCPESCA/MS, 2014.

CATELLA, A.C.; PETRERE, M. Feeding patterns in a fish community of baia da Onça, a floodplain lake of the Aquidauana River, Pantanal, Brazil. Fisheries Management and Ecology, 1996. p. 229-237.

COLLISCHONN, W. et al. Em busca do hidrograma ecológico. XVI Simpósio Brasileiro de Recursos Hídricos, 2005, João Pessoa/PB.

CONEXÃO PLANETA. Mercado brasileiro de energia solar espera crescimento de 300\% em 2016.

DA SILVA, C.J. Ecological basis for the management of the Pantanal - Upper Paraguay River Basin. In: SMITS, A.J.M. et al. New approaches to river management, Leiden, Netherlands: Backhuys Publishers, 2000. p. 97-117.

DA SILVA, C.J.; SILVA, J.A.F. No ritmo das águas do Pantanal. São Paulo: NUPAUB/USP, 1995

EPE. Empresa de Pesquisa Energética. Ministério de Minas e Energia. Nota Técnica no 127/2015: Panorama sobre os resultados do 10 Leilão de Energia de Reserva 2015. Expansão de Geração, 2015.

FERNANDES, R. et al. Effects of the hydrological regime on the ichthyofauna of riverine environments of the Upper Paraná River Floodplain. Brazilian Journal of Biology, v.69, n.2, 2009, p.669-680.

GALDINO, S., VIEIRA, L.M.; PELLEGRIN, L.A. Impactos ambientais e socioeconômicos na Bacia do Rio Taquari, Pantanal. Corumbá: Embrapa Pantanal, 2005.

GIRARD, P. Efeito cumulativo das barragens no Pantanal: mobilização para conservação das áreas úmidas do Pantanal e Bacia do Araguaia. Campo Grande, MS: Instituto Centro Vida, 2002.

HAMILTON, S.K. Human impacts on hydrology in the Pantanal wetland of South America. Water Sci. Technol., v.45, 2002, p.35-44.

HAMILTON, S.K. et al. An anoxic event and other biogeochemical effects of the Pantanal wetland on the Paraguay River. Limnology and Oceanography, 42, 1997, 257-272.

INSTITUTO ACENDE BRASIL. Análises de Leilões. 8 Leilão de Energia de Reserva. Análise Pós-Leilão, 2015.

JUNK, W.J., BAYLEY, P.B.; SPARKS, R.E. The Flood Pulse Concept in River-Floodplain Systems. In: DODGE, D. (ed.): Proceedings of the International Large River Symposium (LARS). Canadian Special Publication of Fisheries and Aquatic Sciences, v.106, 1989, p.110-127.

JUNK, W.J.; NUNES DA CUNHA, C. Pantanal: a large South American wetland at a crossroads. Ecological Engineering, 2005, v.24, p.391-401.
MEA. Millennium Ecosystem Assessment. Ecosystems and Human Well-Being: Wetlands and Water - Synthesis. World Resources Institute, Washington, DC, 2005a.

MEA. Millennium Ecosystem Assessment. Natural Assets and Human Well-Being: Living Beyond Our Means - Statement from the Board. World Resources Institute, Washington, DC, 2005b.

MONITORAMENTO das alterações da cobertura vegetal e uso do solo na Bacia do Alto Paraguai - Porção Brasileira Período de Análise: 2012 a 2014. Brasília: Instituto SOS Pantanal; WWF - Brasil. Relatório Técnico.

MORAES, A.S. Pecuária e conservação do Pantanal: análise econômica de alternativas sustentáveis - o dilema entre benefícios privados e sociais. 2008. 265 f. Tese Doutorado em Economia. Universidade Federal de Pernambuco, UFPE, 2008.

MORAES, A.S.; SEIDL, A.F. Perfil dos pescadores esportivos do sul do Pantanal. Circular Técnica, 24. Corumbá: Embrapa Pantanal, 2000.

Acesso em: 03 mar. 2018.

MOURÃO, G. M. et al. 2013. Respostas ecológicas de longo prazo a variações plurianuais das enchentes no Pantanal: sítio 2. In: TABARELLI, M; et al. (Org.) PELD/CNPq - Dez anos do Programa de Pesquisas Ecológicas de Longa Duração no Brasil: achados, lições e perspectivas. Recife: Ed. Universitária UFPE, 2013, p. 89-116.

MPF. Ministério Público Federal - Procuradoria da República no Município de Corumbá/MS. Ata de Audiência Pública: Empreendimentos hidrelétricos na Bacia do Alto Paraguai (BAP) - a exploração energética e a integridade ecológica do Pantanal. 19p. Campo Grande, MS, 20 de julho de 2010.

NUNES DA CUNHA, C.; PIEDADE, M.T.F.; JUNK, W.J. Classificação e delineamento das áreas úmidas brasileiras e de seus macrohabitats. Cuiabá: EdUFMT, 2015.

OLIVEIRA, M.D.; CALHEIROS, D.F. Flood pulse influence on phytoplankton communities of the south Pantanal floodplain, Brazil. Hydrobiology, v.427, 2000. p.102-112.

OLIVEIRA, M. D.. Oxygen depletion events control the invasive golden mussel (Limnoperna fortunei) in a tropical floodplain. Wetlands, v.30, n.4, p.705-716.

OLIVEIRA, M.D.. Abiotic factors controlling the establishment and abundance of the invasive golden mussel Limnoperna fortunei. Biological Invasions, 2011, 13:717-729.

PEREIRA, E.B. et al. Atlas brasileiro de energia solar. São José dos Campos: INPE, 2006.

POFF, L.N. et al. The natural flow regime: a paradigm for river conservation and restoration. BioScience, v.47, 1997. p.769-784.

POSTEL, S.; RICHTER, B. Rivers for life: Managing water for people and nature. Washington: Island Press, 2003.

POTT, A.. Plant diversity of the Pantanal wetland. Brazilian Journal of Biology, v.71, n.1, p.265-273, 2011a. 
POTT, A.. Aquatic macrophyte diversity of the Pantanal wetland and upper basin. Brazilian Journal of Biology, 2011, v.71, n.1, p.255-263, 2011 b.

RAMSAR. Ramsar Convention Secretariat. The annotated Ramsar List of Wetlands of International Importance - Brazil, 2016.

REZENDE, A. T.; FURIAN, S; VICTORIA, R. L.; MASCRÉ C.; VALLES, V.; BARBIERO. L.. Hydrochemical variability at the Upper Paraguay Basin and Pantanal Wetland. Hydrol. Earth. Syst. Sci., v.16, 2012, p.2723-2737.

SALES, C.J.D.; UHLIG, A. 2015. Expansão da geração na era pós-hidrelétrica. Instituto Acende Brasil. Canal Energia Artigos e Entrevistas, 2015.

SANTOS, M.T. et al. Factors structuring the spatial distribution of chironomidae larvae community in the floodplain of the Northern Pantanal, Brasil. Acta Limnologica Brasiliensia, v.25, n.2, 2013. p.131-139.

SCREMIN-DIAS, E.A.; LORENZ-LEMKE, A.P.; OLIVEIRA, A.K.M. The floristic heterogeneity of the Pantanal and the occurrence of species with different adaptive strategies to water stress. Brazilian Journal of Biology, v.71, n.1 (suppl.), 2011, p. 275-282.

SEIDL, A.F.; MORAES, A.S. Global valuation os ecosystem services: application to the Pantanal da Nhecolandia, Brazil. Ecological Economics, v.33, 2000, p.1-6.

SHRESTHA, R.K.; SEIDL, A.F.; MORAES, A.S. Value of recreational fishing in the Brazilian Pantanal: a travel cost analysis using count data models. Ecological Economics, v.42, 2002, p. 289-299.

\section{SILVA, A; SOUZA FILHO, E.E.; NEVES; S.M.A.S. Erosão} marginal e sedimentação no rio Paraguai no município de Cáceres (MT). Revista Brasileira de Geociências, v.41, n.1, 2011, p.76-84.
SILVA, J.S.V. et al. Evolution of deforestation in the Brazilian Pantanal and surroundings in the timeframe 1976-2008. Geografia, v.36, número especial, 2011, p.35-55.

SILVEIRA, A.; MOURA, R.M.P.; ANDRADE, N.L.R. Determinação da $Q_{7,10}$ para o rio Cuiabá, Mato Grosso, Brasil e comparação com a vazão regularizada após a implantação do reservatório de Aproveitamento Múltiplo de Manso. XXX Congresso Interamericano de Ingeniería Sanitaria y Ambiental, 26-30 nov. 2006, Punta del Este Uruguay.

SOUZA FILHO, E.E. As barragens na bacia do rio Paraguai e a possível influência sobre a descarga fluvial e o transporte de sedimentos. Bol. Geogr., v.31, n.1, 2013, p.117-133.

UNESCO. Biosphere Reserve Information - The Pantana Biosphere Reserve. MAB - Man and Biosphere Programme. Biosphere Reserves Directory. 2000a.

UNESCO. World Heritage by United Nations - Pantanal Conservation Complex on the World Heritage List, 2000b.

WCD. World Comission on Dams, 2000.

WELCOMME, R.L. Relationships between fisheries and the integrity of river systems. Regulated Rivers: Research \& Management, v.11, 1995, p.121-136.

WERNER JR. et al. Remanejamento da população atingida pelo reservatório do aproveitamento múltiplo de Manso MT. XXV Seminário Nacional de Grandes Barragens. Comitê Brasileiro de Barragens. Salvador, 12-15 out 2003.

WWF. Monitoramento da cobertura vegetal e uso do solo da Bacia do Alto Paraguai (2016). WWF- Brasil. Universidade Católica Dom Bosco, Fundação Tuiuiú. Brasília, 2017.

ZEILHOFER, P.; MOURA, R.M. Hydrological changes in the northern Pantanal caused by the Manso dam: Impact analysis and suggestions for mitigation. Ecological Engineering, v.35, 2009. p.105-117.

A CBPC - Companhia Brasileira de Produção Científica (CNPJ: 11.221.422/0001-03) detém os direitos materiais desta publicação. Os direitos referem-se à publicação do trabalho em qualquer parte do mundo, incluindo os direitos às renovaç̃ões, expansões e disseminações da contribuiç̃o, bem como outros direitos subsidiários. Todos os trabalhos publicados eletronicamente poderão posteriormente ser publicados em coletâneas impressas sob coordenação da Sustenere Publishing, da Companhia Brasileira de Produção Científica e seus parceiros autorizados. Os (as) autores (as) preservam os direitos autorais, mas não têm permissão para a publicação da contribuição em outro meio, impresso ou digital, em português ou em tradução. 